\title{
Structure and Properties of Porous Ceramics Obtained from Aluminum Hydroxide
}

\author{
R. Levkov ${ }^{1,2, a)}$ and S. Kulkov ${ }^{1,2,3, b)}$ \\ ${ }^{1}$ Institute of Strength Physics and Material Sciences SB RAS, Academicheskii Pr. 2/4, Tomsk, 634055 Russia \\ ${ }^{2}$ Tomsk Polytechnic University, Lenin Avenue 30, Tomsk, 634050 Russia \\ ${ }^{3}$ Tomsk State University, Lenin Avenue 36, Tomsk, 634050 Russia \\ a) Corresponding author: Levkov.r.v@mai.ru \\ b) Kulkov@ispms.ru
}

\begin{abstract}
In this paper the study of porous ceramics obtained from aluminum hydroxide with gibbsite modification is presented. The dependence of porosity and mechanical characteristics of the material sintered at different temperatures was studied. It was shown that compressive strength of alumina ceramics increases by 40 times with decreasing the pore volume from 65 to $15 \%$. It was shown that aluminum hydroxide may be used for pore formation and pore volume in the sintered ceramics can be controlled by varying the aluminum hydroxide concentration and sintering temperature. Based on these results one can conclude that the obtained structure is very close to inorganic bone matrix and can be used as promising material for bone implants production.
\end{abstract}

\section{INTRODUCTION}

The development of material based on porous oxides with high strength is a fundamental challenge to modern materials [1]. Ceramics with a similar structure can be applied to produce filters, catalyst supports, membranes etc. [2]. Porous ceramics is also interesting for medical use because its structure is close to bone tissue.

The traditional method of creating highly porous materials is based on "burn-pore-forming" additives [3]. On the one hand this method is effective in terms of management of the pore volume, but on the other hand the possible formation of carbon on the inner surfaces of porous material is unacceptable for the manufacture of bio-implants and can lead to rejection of the implant. To form a multi-level pore structure without addition of pore-former one can use the method of decomposition of components, for example, the hydroxides to oxides, accompanied by the release of gas and, as a consequence, the formation of porosity [4]. This method based on the decomposition of aluminum hydroxide to the oxide has been known for a long time [5], but there is no data on the regulation of the pore space volume and the dependence of the pore space formation sintered at different temperatures, particle size of initial powders, as well as no data about dependences of the strength of the ceramic with changing of porosity.

The aim of this work is to study formation of porous structures in ceramic synthesized from aluminum hydroxide due to decomposition of hydroxide to the oxide.

\section{MATERIALS AND EXPERIMENTAL PROCEDURE}

Aluminum hydroxide with gibbsite modification $\mathrm{Al}_{2} \mathrm{O}_{3} \cdot 4 \mathrm{H}_{2} \mathrm{O}$ obtained by the decomposition of the aluminates solution was used as a starting component. Cylindrical form samples were pressed at $20 \mathrm{kN}$ load, sintered in air at 1300,1400 and $1500^{\circ} \mathrm{C}$, with isothermal one hour holding. The structure, morphology, pore space, grain size and phase composition were investigated. The volume of the pore space was estimated by the formula $\theta=\left(\rho_{\mathrm{th}}-\rho_{\mathrm{e}}\right) / \rho_{\mathrm{K}} \times$ $100 \%$, where $\rho_{\text {th }}$ - the theoretical density material, $\rho_{\mathrm{e}}$ - experimental density of the material.

Physics of Cancer: Interdisciplinary Problems and Clinical Applications (PC'16)

AIP Conf. Proc. 1760, 020042-1-020042-4; doi: 10.1063/1.4960261

Published by AIP Publishing. 978-0-7354-1418-1/\$30.00 


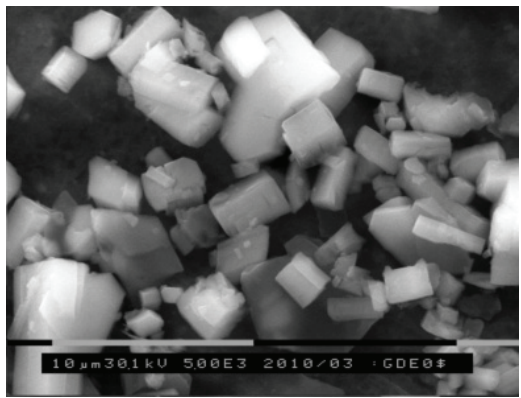

(a)

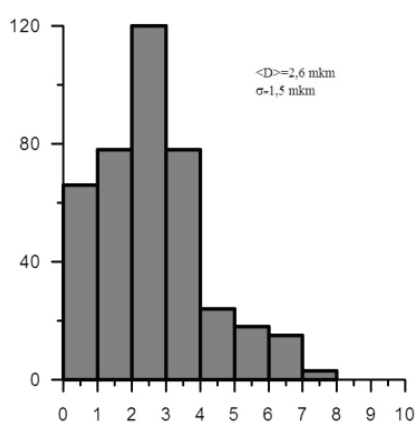

(b)

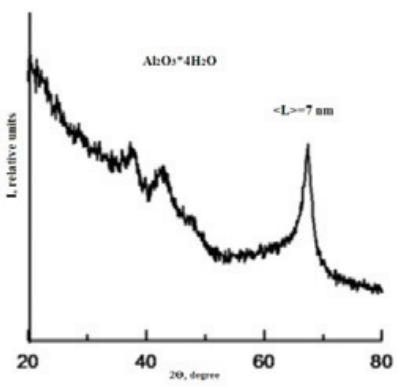

(c)

FIGURE 1. (a) The SEM image of the aluminum hydroxide powder obtained by the decomposition of the aluminate solution, (b) the distribution of powder particle size, (c) a powder X-ray diffraction

The pore structure of ceramics and morphology of the powder was investigated using scanning electron microscope (SEM) Philips-SEM 515 and optical microscope. The mean pore size of ceramics and the powder particles were calculated by the secant method [5].

$\mathrm{X}$-ray diffraction studies were carried out on X-ray diffractometer with filtered $\mathrm{CuK} \alpha$ radiation. Diffraction spectra were obtained in the range of angles $2 \theta=20^{\circ}-80^{\circ}$ with a step $\Delta(2 \theta)=0.05^{\circ}$, the exposure time was selected to achieve accuracy better when $0.5 \%$. Compression testing of ceramics samples was carried out on universal test machine "Devotrans" with strain rate $2 \times 10^{-4} \mathrm{~s}^{-1}$.

\section{RESULTS AND DISCUSSION}

Figure 1a shows an image of initial powder particles of aluminum hydroxide. The particles have good faceting. Figure $1 \mathrm{~b}$ shows the size distribution of particles, the average particle size of the powder was $2.6 \mu \mathrm{m}$.

On the XRD pattern (Fig. 1c) reflexes have a large width and only three X-ray maximum are clearly visible. Their angular position corresponds to the strongest reflections of the hydrated oxide of aluminum of the composition $\mathrm{Al}_{2} \mathrm{O}_{3} \times 4 \mathrm{H}_{2} \mathrm{O}$ [6]. The widening of X-ray peaks could be caused by a small size of the coherent diffracting domain (CDD), or concentration inhomogeneity of powder according to the degree of hydration of $\mathrm{Al}_{2} \mathrm{O}_{3}$. These factors are affected on the specific powder surface - the specific surface of the powder is $173 \mathrm{~m}^{2} / \mathrm{g}$, the similar data were obtained in [7].

According to the EDAX analysis of the samples after sintering the content of oxygen was $59.1 \pm 2.3 \%$ (at.) and the content of aluminum was $40.9 \pm 1.3 \%$ (at.) which corresponds to chemical formula of aluminum oxide. No impurities in ceramics were detected.

The structure of sintered ceramics is presented in Fig. 2. As one can see grains of aluminum oxide have a spherical shape and independently to sintering temperature all samples are characterized by the presence of interparticle porosity.
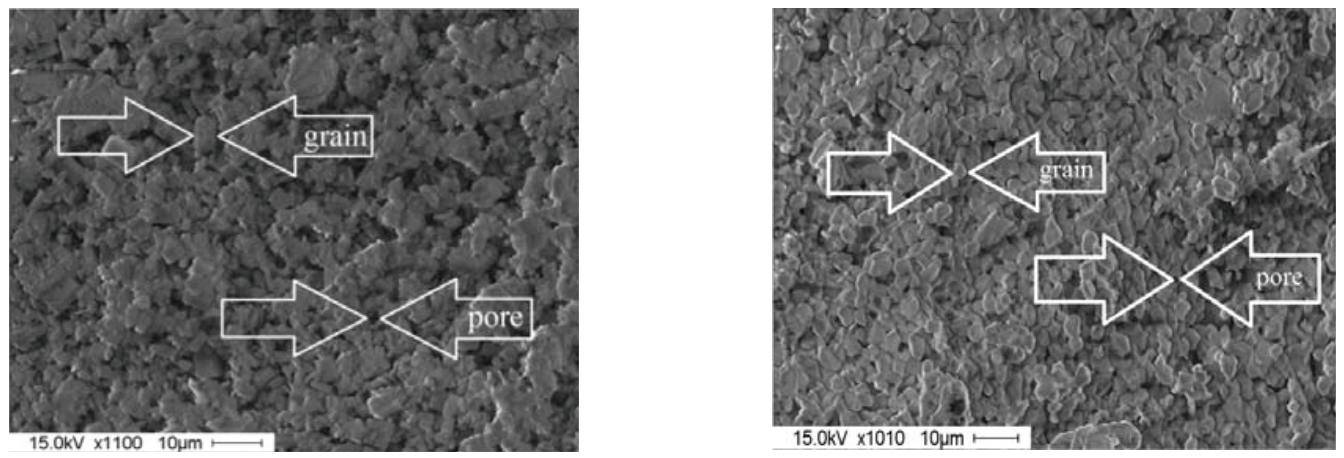

FIGURE 2. Ceramic structure after sintering at 1300 and $1500^{\circ} \mathrm{C}$ 


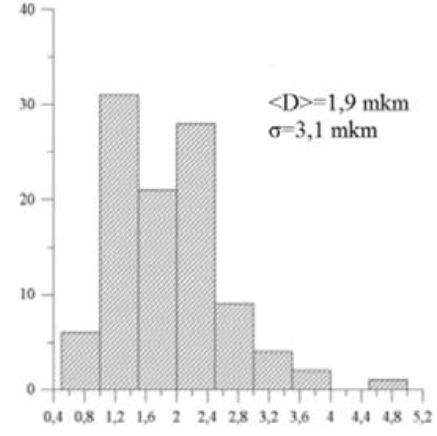

(a)

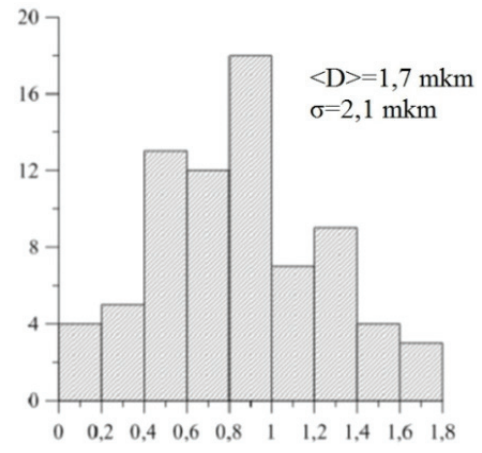

(b)

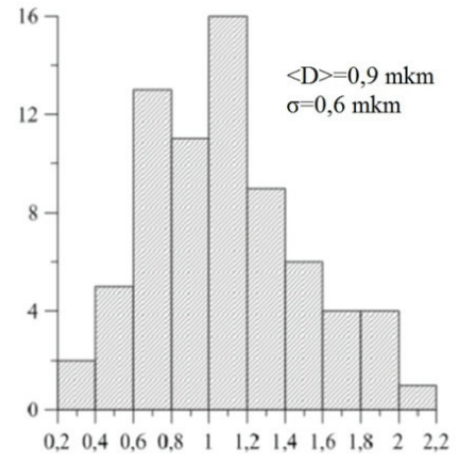

(c)

FIGURE 3. Pore size distribution, the sintered ceramics at the temperatures: (a) 1300 , (b) 1400 , (c) $1500^{\circ} \mathrm{C}$

It was also observed that the increase in sintering temperature leads to a decrease in the inter-particle pore size (Fig. 4a) the pore sizes distributions for samples with increasing sintering temperature are decreasing (Fig. 3).

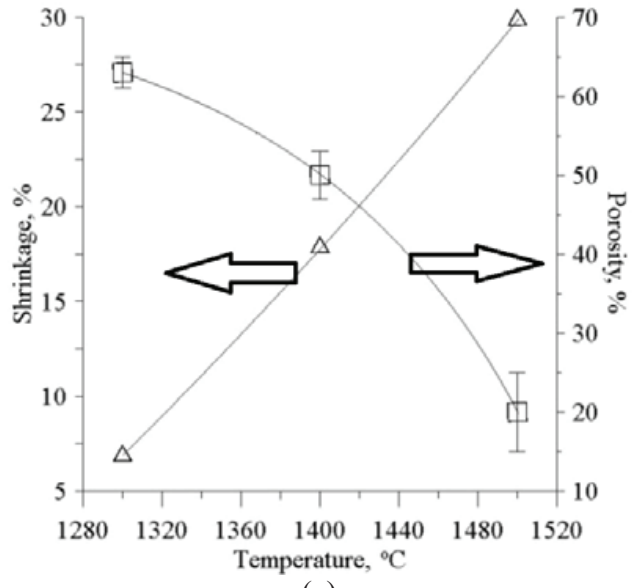

(a)

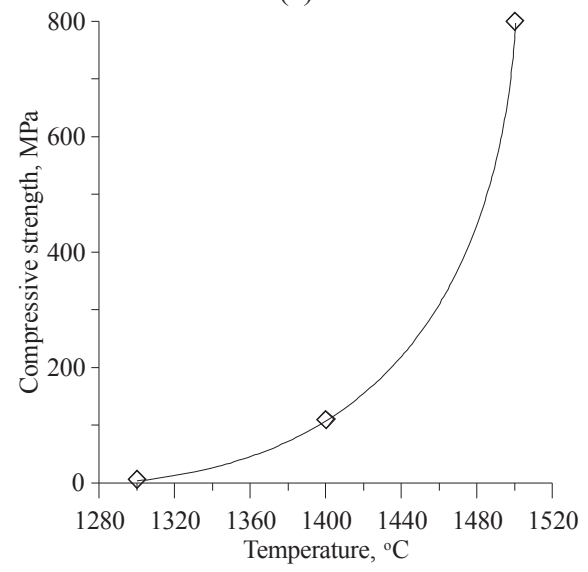

(c)

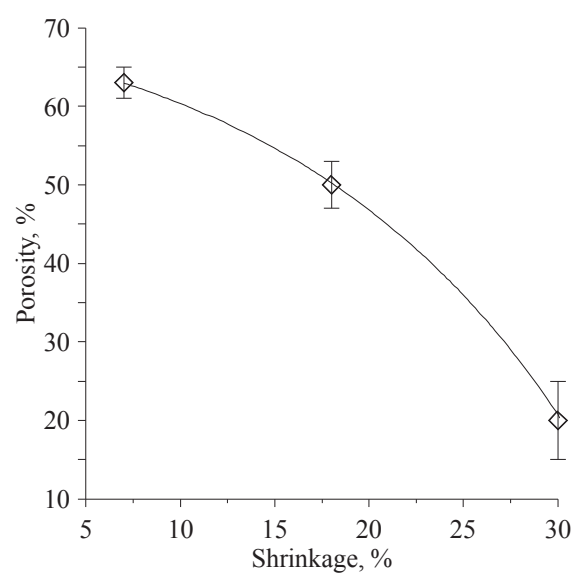

(b)

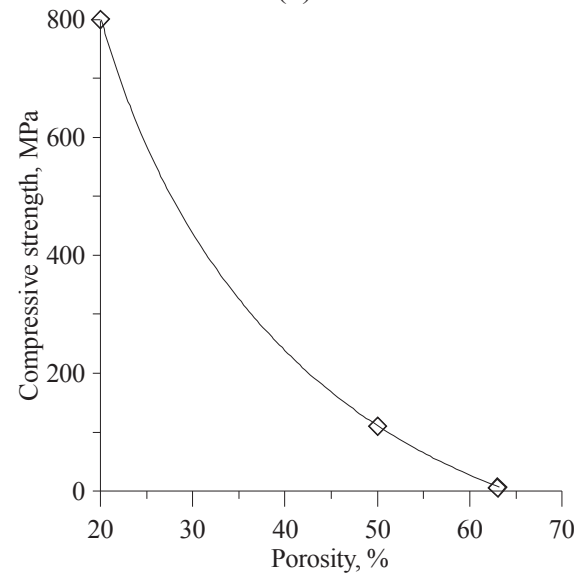

(d)

FIGURE 4. (a) Dependency of shrinkage porosity on sintering temperature, (b) dependence of shrinkage porosity, (c) the dependence of the strength of the sintering temperature, (d) the ultimate strength of the dependence of porosity 
In Fig. 4a the results of shrinkage of the samples are shown: it has a linear dependence on sintering temperature. The results of mechanical testing are shown in Fig. 3. One can observe a significant increase in the compressive strength with increasing sintering temperature associated with the decrease in the pore space volume.

Such dependencies are usually described by exponential equations $y=\exp (\alpha x)$ [8]. A similar analysis conducted in [9] for the porous zirconia showed that $\alpha$ changes in the range from -7 , for pores with the size much more than mean grain size, to -4 , for pores with the size comparable with mean grain size.

In our case strength vs. porosity dependence re-plotted with double logarithmic coordinates resulted that $\alpha=-10.5$. This high value may be associated with weak inter-grain connections, or the fact that in [10] ceramic samples obtained from zirconia. Therefore, it is necessary to investigate alumina ceramics with other experimental conditions: increased sintering temperature, isothermal exposure, which will ensure the grain boundary strength increase.

\section{CONCLUSION}

The method of forming pores, the pore-forming burnout comparisons decomposition during sintering, allows obtaining the same porosity as in the organic burnout material about $15-65 \%$. Porosity decreases with increase of the sintering temperature. The pore size decreases from 1.9 to $0.9 \mu \mathrm{m}$ and the dispersion decreases from 3.1 to $0.6 \mu \mathrm{m}$. It was shown that the compressive strength increases with increasing sintering temperature, minimum compression strength is $20 \mathrm{MPa}$ for sintering temperature $1300^{\circ} \mathrm{C}$ and the maximum $800 \mathrm{MPa}$ for $1500^{\circ} \mathrm{C}$ besides with decreasing pore volume from 65 to $15 \%$.

Based on these results, we can conclude that the aluminum hydroxide can be used as pore formation material for sintering ceramics with controlled porosity. The obtained alumina structure is very close to inorganic bone matrix and is promising material for bone implants.

\section{ACKNOWLEDGMENTS}

This work was financially supported by Grant No. 14.607.21.0069-RFMEFI60714X0069 of Ministry of Science and Education of RF.

The study reported in this article was conducted according to accepted ethical guidelines involving research in humans and/or animals and was approved by an appropriate institution or national research organization. The study is compliant with the ethical standards as currently outlined in the Declaration of Helsinki. All individual participants discussed in this study, or for whom any identifying information or image has been presented, have freely given their informed written consent for such information and/or image to be included in the published article.

\section{REFERENCES}

1. R. Ahmad, J. H. Ha, and I. H. Song, Synthesis of open-cell particle-stabilized $\mathrm{Al}_{2} \mathrm{O}_{3}$ foam using $\mathrm{Al}(\mathrm{OH})_{3}$ particles, Scripta Mater. 76, 85-88 (2014).

2. Y. Heo, H. Im, J. Kim, and J. Kim, The influence of $\mathrm{Al}(\mathrm{OH})_{3}$-coated graphene oxide on improved thermal conductivity and maintained electrical resistivity of $\mathrm{Al}_{2} \mathrm{O}_{3}$ /epoxy composites, J. Nanoparticle Res. 14(10), 1-10 (2014).

3. A. D. Souza, C. C. Arruda, L. Fernandes, M. L. Antunes, P. K. Kiyohara and R. Salomão, Characterization of aluminum hydroxide $\left(\mathrm{Al}(\mathrm{OH})_{3}\right)$ for use as a porogenic agent in castable ceramics, J. Eur. Ceramic Soc. 35(2), 803$812(2015)$

4. M. Goudarzi, D. Ghanbari, M. Salavati-Niasari, and A. Ahmadi, Synthesis and characterization of $\mathrm{Al}(\mathrm{OH})_{3}, \mathrm{Al}_{2} \mathrm{O}_{3}$ nanoparticles and polymeric nanocomposites, J. Cluster Sci. 27(1), 25-38 (2016).

5. N. L. Savchenko, I. N. Sevostyanova, T. U. Sablina, L. Molnar, R. Geber, L. A. Gomze, S. N. Kulkov, and L. N. Gomze, The influence of porosityon the elasticity and strength of alumina ceramics, J. Silicate Based Composite Mater. Epitoanyag 2, 44-47 (2014).

6. V. V. Roerich, A. V. Krut'ko, A. D. Lastevsky, D. A. Kozlov, A. R. Avetisyan, A. M. Aronov, and N. A. Rychkova, The ventral interbody fusion in the lower cervical spine porous bioceramic implant, Surgery 12(1), 63-68 (2015).

7. Y. Yang, S. Shimai, Y. Sun, M. Dong, H. Kamiya, and S. Wang, Fabrication of porous $\mathrm{Al}_{2} \mathrm{O}_{3}$ ceramics by rapid gelation and mechanical foaming, J. Mater. Res. 28, 15-19 (2013).

8. L. Jing, K. Zuo, Z. Fuqiang, X. Chun, F. Yuanfei, D. Jiang, and Y. P. Zeng, The controllable microstructure of porous $\mathrm{Al}_{2} \mathrm{O}_{3}$ ceramics prepared via a novel freeze casting route, Ceramics Int. 36(8), 2499-2503 (2010).

9. S. P. Buyakova, Han Vey, Lee Dong, Zhen Hayyun, T. Yu. Sablina, A. G. Melnikov, and S. N. Kul'kov, The mechanical behavior of porous zirconia with active compression deformation, J. Tech. Phys. 44-48 (1999).

10. S. N. Kulkov and S. P. Buyakova, Rheology and porosity effect on mechanical propertiesof zirconia ceramics. Journal of Silicate based and composite materials, Epitoanyag 4, 155-158 (2015). 